\title{
Laparoscopic grasper for intramedullary biopsy: a technique to improve tissue sampling
}

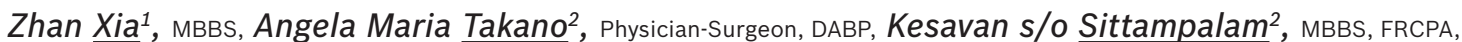
Tet Sen $\underline{\text { Howe }}^{1}$, MBBS, FRCS

\begin{abstract}
Reaming samples are usually sent for histological testing to establish or confirm the primary source of malignancy while intramedullary nailing is performed for impending or established pathological fracture of the long bones. However, this conventional technique of sampling does not always yield accurate results. Herein, we introduce a technique for intramedullary biopsy using a laparoscopic grasper under image intensifier guidance. This novel technique was applied in three cases, and the tissue samples obtained successfully established or confirmed the primary source of malignancy. In comparison, reaming samples obtained via the conventional method showed negative findings in one case and tumour cells that were of poor sample quality in another case. We opine that this new technique is an effective and reproducible method that could improve tissue sampling and achieve a more reliable histological diagnosis.
\end{abstract}

Keywords: intramedullary biopsy, laparoscopic grasper, long bone, pathological fracture, tissue sampling

\section{INTRODUCTION}

For patients with impending or established pathological fracture of the long bones, intramedullary nailing is usually recommended to stabilise the bone in order to relieve pain and improve mobility. During the procedure, reaming samples are usually sent for histological examination to establish or confirm the primary source of malignancy. However, the accuracy of this method may not be satisfactory - Subramanian et al ${ }^{(1)}$ reported a sensitivity of only $61 \%$, while Hassan et $\mathrm{al}^{(2)}$ demonstrated that only $60 \%$ of samples obtained from reaming establish a definitive diagnosis. However, it is essential for accurate histological diagnosis to be reached, in order to stage the disease and optimise therapies for cancer patients. Moreover, missed diagnoses may result in further investigations and delays in the introduction of treatment modalities crucial for improving outcomes.

To improve tissue sampling, we introduced a technique of intramedullary biopsy using a laparoscopic grasper under image intensifier guidance. This technique, widely applicable for lesions of the long bones such as the femur, tibia and humerus, makes use of laparoscopic graspers of appropriate sizes.

\section{CASE REPORT}

This novel technique was applied to three cases with pending or established pathological fractures of the long bones. During intramedullary nailing of the long bones, a standard approach and entry point was used. The cortex was breached with a drill or an awl. A guidewire was then inserted into the proximal part of the lesion under the guidance of an image intensifier, and the canal proximal to the lesion was reamed. An appropriately sized laparoscopic grasper (Fig. 1) was then inserted, and an adequate quantity of high-quality tissue samples was obtained under image intensifier guidance (Figs. 2a \& b). Based on our experience, two or three tissue samples need to be obtained; more tissue samples

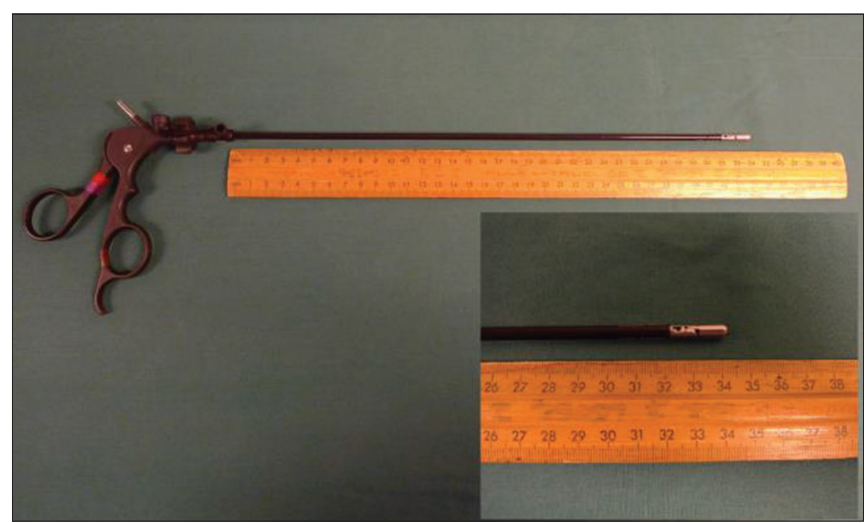

Fig. 1 Case 1. Photograph shows the laparoscopic grasper (measuring $34 \mathrm{~cm}$ in length) that was applied to obtain the tissue samples of bone lesion through the femoral cavity of the patient.
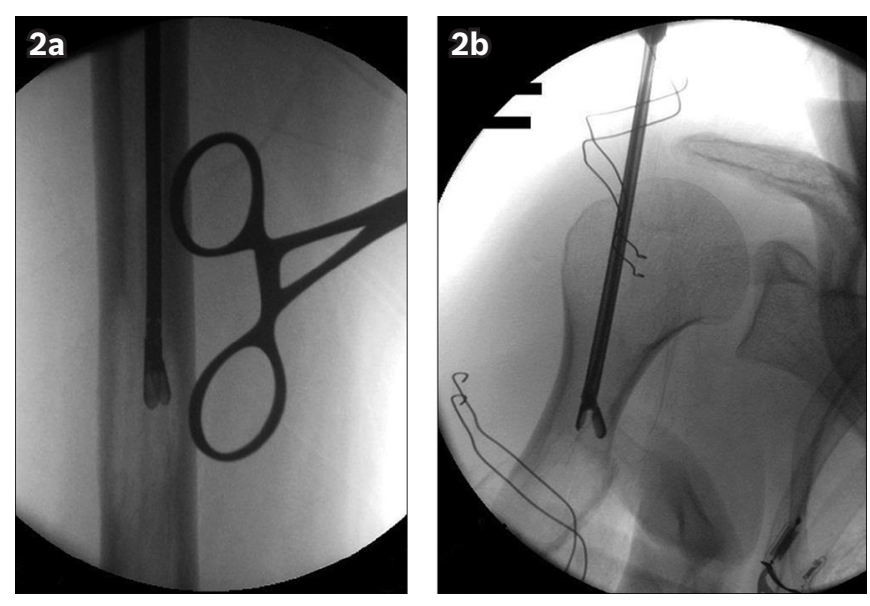

Fig. 2 Intraoperatively and under image intensifier guidance, the laparoscopic grasper was inserted through (a) the right femoral canal of Case 1; and (b) the right humeral canal of Case 2, to obtain the tissue samples.

were taken if some parts of the lesion were of particular interest to the surgeon. Intraoperatively, the tissue samples obtained 
Table I. Details of the three cases.

\begin{tabular}{llll}
\hline Parameter & Case 1 & Case 2 & Case 3 \\
\hline $\begin{array}{l}\text { Age (yrs)/gender } \\
\text { Symptoms }\end{array}$ & $\begin{array}{l}\text { 78/female } \\
\text { Right thigh pain for 4 mths }\end{array}$ & $\begin{array}{l}27 / \text { female } \\
\text { Right arm pain for 2 days }\end{array}$ & $\begin{array}{l}57 / \text { female } \\
\text { Severe right arm pain, subsequent } \\
\text { to a 'crack' sound from the left } \\
\text { arm when supporting her body } \\
\text { with the right arm while in bed }\end{array}$ \\
$\begin{array}{l}\text { Previous history } \\
\text { of malignancy }\end{array}$ & Nil & Nil & Rectal cancer \\
$\begin{array}{l}\text { Radiographic } \\
\text { findings }\end{array}$ & $\begin{array}{l}\text { Intraosseous lytic lesion in the } \\
\text { mid-shaft of the right femur, with } \\
\text { erosion of the bony cortical linings }\end{array}$ & $\begin{array}{l}\text { Fracture in the proximal third of } \\
\text { the right humerus, centred at a } \\
\text { well-defined intramedullary lytic }\end{array}$ & $\begin{array}{l}\text { Oblique fracture in the proximal } \\
\text { third of the left humerus, with no } \\
\text { obvious lytic lesion }\end{array}$ \\
$\begin{array}{l}\text { Histology of } \\
\text { grasped tissue } \\
\text { samples } \\
\text { Histology of } \\
\text { reaming samples }\end{array}$ & $\begin{array}{l}\text { Positive for malignancy; strongly } \\
\text { positive TTF-1 reaction (metastatic } \\
\text { adenocarcinoma from the lung) } \\
\text { Positive for malignancy } \\
\text { (metastatic adenocarcinoma from } \\
\text { the lung) }\end{array}$ & $\begin{array}{l}\text { Positive for bone cyst } \\
\text { (simple bone cyst) }\end{array}$ & $\begin{array}{l}\text { Positive for malignancy } \\
\text { (metastatic adenocarcinoma from } \\
\text { the colon) }\end{array}$ \\
\hline
\end{tabular}

TTF-1: thyroid transcription factor-1
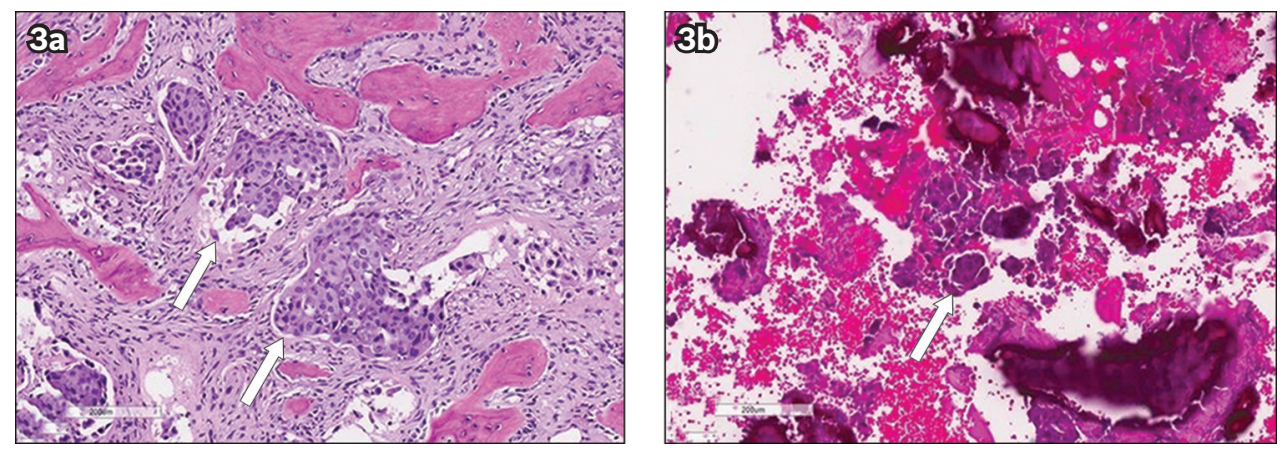

Fig. 3 Case 1. (a) Photomicrograph of the grasped tissue sample shows preservation of the bone architecture with multiple nests of metastatic carcinoma (arrows) and preserved histomorphology, which favours the diagnosis of adenocarcinoma. (b) Photomicrograph of reaming sample shows fragmentation of the bone with 'burn' artefact, haemorrhage, and disruption of the tissue architecture, with tumour cells (arrow) seen in the centre (Haematoxylin \& eosin, × 10 for both images).
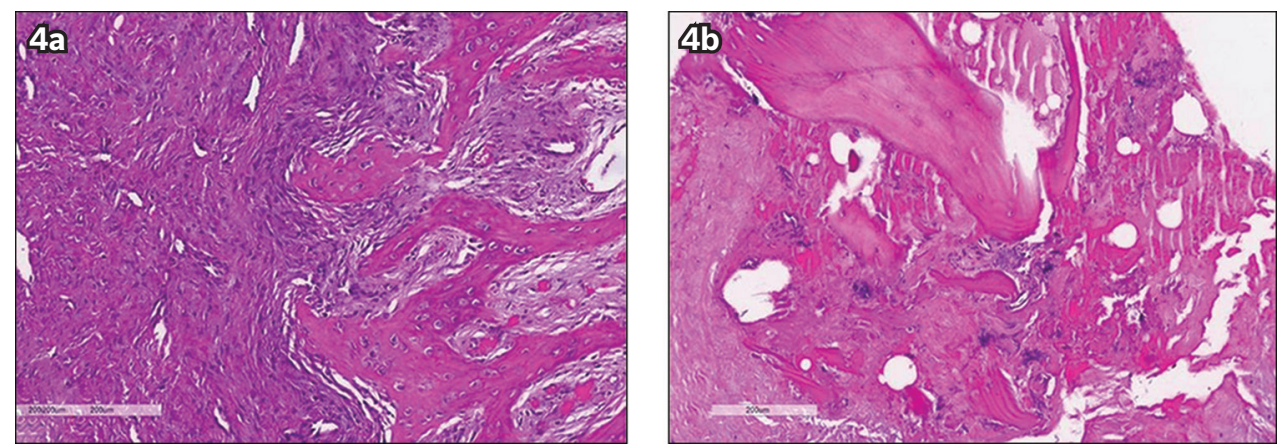

Fig. 4 Case 2. (a) Photomicrograph of the grasped tissue sample shows a fibrous wall with new bone formation, but with no inflammation, granulomata or cementum-like material seen. These features are consistent with a simple cyst. (b) Photomicrograph of the reaming sample shows a fracture site with haemorrhage and necrotic bone (Haematoxylin \& eosin, $\times 10$ for both images).

via this technique and the reaming samples obtained from the conventional method were sent for histological testing.

The details of the three cases are presented in Table I. In Case 1, although the tissue samples obtained via this technique and the reaming samples both showed tumour cells (Figs. 3a \& b, respectively), the grasped tissue samples were found to be of better histological quality, as their tissue structures were well preserved without thermal or other artefact compared to the reaming samples. On further thyroid transcription factor-1 (TTF-1) test, the grasped samples in Case 1 showed a strongly positive reaction consistent with adenocarcinoma of the lung, and this was vital for the final histological diagnosis. In Case 2, the grasped tissue samples revealed histological features consistent with simple bone cyst, while reaming samples revealed negative findings for bone cyst (Figs. 4a \& b, respectively). In Case 3, both the grasped tissue samples and reaming samples showed tumour cells. 


\section{DISCUSSION}

Intramedullary nailing, first introduced by Küntscher in $1939{ }^{(3)}$ is a standard treatment for most closed and impending pathologic fracture of the long bones. Intramedullary reaming is usually performed prior to nail insertion. This allows for appropriate shaping of the medullary canal to facilitate the insertion of a larger nail. Reaming is also the time-tested method of tissue sampling to establish or confirm the nature of the bone lesion. However, the process of reaming significantly reduces the sensitivity of histological testing of reaming samples. During the process of intramedullary reaming, multiple mechanisms that could affect the accuracy of the test for reaming samples may be involved. First, reaming leads to direct mechanical destruction of the tissue. During this process, tissues and cells at the lesion site may also be destroyed together with normal tissues, thus affecting the sample quality for histological testing. Second, it has been demonstrated by several studies that intramedullary reaming causes considerable elevation of temperature. ${ }^{(4)}$ In intramedullary reaming of the femur, the temperature may rise to $40.6^{\circ} \mathrm{C}-67^{\circ} \mathrm{C}$. ${ }^{(5,6)}$ Matthews and Hirsch's study ${ }^{(7)}$ showed that $56^{\circ} \mathrm{C}$ is the critical temperature at which denaturation of cellular enzymes and thermal injury to the bone occur. Similarly, Eriksson et $\mathrm{al}^{(8)}$ found that a consistent temperature of $47^{\circ} \mathrm{C}-50^{\circ} \mathrm{C}$ lasting for 1 min significantly leads to bone necrosis and impaired bone formation. Likewise, increase in temperature also results in thermal injury to tissues or cells over the lesion site and affects the accuracy of histological testing of reaming samples. Finally, as reaming samples are usually collected from the incision site or reamer blade, procurement is non-targeted, thus making it difficult to differentiate lesion tissues from normal tissues. Thus, this conventional sampling method may result in suboptimal quantity or quality of samples obtained, as the lesion tissues may be largely diluted by normal tissues. Furthermore, these reaming samples sent for histological testing may not even contain any lesion tissues.

To overcome the aforementioned shortcomings and to improve tissue sampling, we introduced the use of a laparoscopic grasper for intramedullary biopsy of pathological fracture of the long bones. Contrary to the conventional sampling method, this novel technique can effectively avoid the problems of direct mechanical destruction of tissue and dilution of sample, and significantly reduce thermal injury to the cells at the lesion site. In addition, this technique is easy to apply and adequate high-quality tissue samples can be grasped with targeted procurement under image intensifier guidance. In the three cases reported herein, all tissue samples obtained via this technique successfully established or confirmed the primary tumour. Reaming samples, on the other hand, showed negative findings in Case 2. In Case 1, although both the grasped tissue samples and reaming samples showed tumour cells, the former is of better histological quality, as our technique minimises sample destruction and dilution, and preserves the tissue structure, which is crucial in improving the sensitivity of further immunohistochemical testing.

In the literature, several techniques have been introduced to improve intramedullary tissue sampling - intramedullary flexible catheter and syringe ${ }^{(9)}$ and intramedullary paediatric chest tube/syringe ${ }^{(10)}$ both obtain samples by aspiration before intramedullary nailing. According to the study by Smith et al, ${ }^{(9)}$ as high as $92.5 \%$ of their samples were diagnostically positive. However, these two techniques are not indicated for initial biopsy of suspected primary lesions due to the possible dissemination of tumour cells. ${ }^{(9,10)}$ Biopsy forceps, such as long bronchial biopsy forceps, ${ }^{(11)}$ oesophageal biopsy forceps ${ }^{(12)}$ and Paterson or Lloyd Davis biopsy forceps, ${ }^{(13)}$ were also applied for intramedullary biopsy. Hebert et al ${ }^{(11)}$ reported positive diagnosis in as high as $71 \%$ of the samples obtained by long bronchial biopsy forceps or similar biting forceps. However, application of biopsy forceps may be limited by its size and rigidity. Our technique, which uses a laparoscopic grasper for intramedullary biopsy, produced more reliable intramedullary biopsy results and was also easy to apply. Although laparoscopic graspers may be limited by their size and rigidity, with the development of materials and manufacturing technique, laparoscopic graspers may eventually be smaller in size and more flexible. ${ }^{(14)}$ Based on our experience, we recommend that laparoscopic grasper be applied after the canal proximal to the lesion is reamed, as this modification of surgical technique will facilitate the insertion of the laparoscopic grasper without significantly affecting the quantity or quality of the tissue samples.

In conclusion, we opine that intramedullary biopsy using laparoscopic graspers is an effective and reproducible technique to improve the yield of tissue sampling and achieve more reliable histological diagnosis. Further studies with a larger number of cases are needed to statistically demonstrate that this novel technique is superior to conventional reaming in improving tissue sampling and accuracy of histological diagnosis.

\section{REFERENCES}

1. Subramanian KN, Ramamurthy C, Ramakrishnan M, Parkinson RW. Histological observation of the reaming samples of bone in patients undergoing intramedullary stabilisation for metastatic bone lesions. J Bone Joint Surg Br 2005; 87-B(Suppl 6).

2. Hassan K, Kalra S, Moran C. Intramedullary reamings for the histological diagnosis of suspected pathological fractures. Surgeon 2007; 5:202-4

3. Küntscher G. [Results and indications for femoral neck nailing (39 SmithPetersen nails)]. Archives of Orthopaedic and Trauma Surgery, with Special Reference to Fracture Teaching and Orthopedic Surgery Technique 1939; 40:282-4. German.

4. Pfeifer R, Sellei R, Pape HC. The biology of intramedullary reaming. Injury 2010; 41 Suppl 2:S4-8.

5. Mueller CA, Rahn BA. Intramedullary pressure increase and increase in cortical temperature during reaming of the femoral medullary cavity: the effect of draining the medullary contents before reaming. J Trauma 2003; 55:495-503.

6. Henry SL, Adcock RA, Von Fraunhofer JA, Seligson D. Heat of intramedullary reaming. South Med J 1987; 80:173-6.

7. Matthews LS, Hirsch C. Temperatures measured in human cortical bone when drilling. J Bone Joint Surg Am 1972; 54:297-308.

8. Eriksson RA, Albrektsson T. The effect of heat on bone regeneration: an experimental study in the rabbit using the bone growth chamber. J Oral Maxillofac Surg 1984; 42:705-11.

9. Smith DG, Behr JT, Hall RF, Dobozi WR. Closed flexible intramedullary biopsy of metastatic carcinoma. Clin Orthop Relat Res 1988:162-4.

10. Johnson JC, Kneisl JS. Bone marrow sampling in pathologic fractures: intramedullary pediatric chest tube technique. J Orthop Trauma 2004; 18:306-9.

11. Hebert J, Couser J, Seligson D. Closed medullary biopsy for disseminated malignancy. Clin Orthop Relat Res 1982:214-7.

12. Wronka KS, Madhusudhan TR, Ramesh B. An innovative technique for long-bone biopsy. Ann R Coll Surg Engl 2010; 92:265.

13. Heaver C, Marsh A. Femoral intramedullary biopsy: improving tissue sampling. Ann R Coll Surg Engl 2011; 93:414-20.

14. No authors. Development of laparoscopic instruments. Minim Invasive Ther Allied Technol 2001; 10:145-54. 